\title{
Структурно-вещественные преобразования красноцветного песчаника в сейсмогенном зеркале скольжения
}

Морозов Ю.А., Смульская А.И., Кулаковский А.Л., Матвеев М.А.

Институт физики Земли им. О.Ю. Шмидта РАН, Москва, тоrozov@ifz.ru

Аннотация. В статье приводятся результаты инструментально-аналитического изучения новообразований в зонках зеркал скольжения по красноцветным песчаникам девонской формации Old Red Sandstones (о. Бьют, Шотландия), как пример структурно-вещественных преобразований полимиктовых осадочных пород приповерхностного залегания в зонах локализованных деформаций при сейсмических скоростях сдвига. Выявлено существенное изменение минерально-фазового и химического состава в сравнении с исходным песчаным матриксом, выраженное в значительном сокращении содержания альбита, полном исчезновении микроклина и в увеличении доли диоксида кремния. Установлено действие процессов гидролиза полевых шпатов, в результате которых сформирована глинка трения мусковит-гематитового состава. Рассмотрены два варианта протекания процессов гидролиза полевых шпатов, сопровождающиеся формированием гематита и приращением доли $\mathrm{SiO}_{2}$, для которых расписаны реакции и рассчитаны. их объемные эффекты. Зафиксировано уплотнение среды в глинке трения на 135 \%. Обсуждается возможное влияние этих преобразований на режим сейсмической подвижки, ее динамику и причины возникновения при этом механической неустойчивости в разломе.

Ключевые слова: зеркала скольжения, глинки трения, гидролиз полевых шпатов, сейсмическая подвижка, механическая неустойчивость.

\section{Structural and material transformations of the Old Red Sandstones in the seismic slickensides}

\author{
Morozov Yu.A., Smulskaya A.I., Kulakovskij A.L., Matveev M.A. \\ Schmidt Institute physics of the Earth RAS, Moscow, morozov@mail.ru
}

Abstract. The article presents results of instrumental and analytical studies of neoplasms in the slickenside zones on the Old Red Sandstones (Isle of Bute, Scotland), as an example of structural and material transformations of polymictic sedimentary rocks in the localized deformation zones at seismic shear rates. A significant change in the mineral phase and chemical composition was found in comparison with the initial sand matrix expressed in a significant decrease in the albite content, the complete disappearance of the microcline and an increase in the silicon dioxide proportion. The feldspar hydrolysis effect, which resulted in the formation of muscovite-hematite gouge has been established. Two variants of the feldspar hydrolysis process accompanied by the hematite formation and the increment of the $\mathrm{SiO} 2$ contents, are considered. The negative volume effect for these reactions is calculated at about $135 \%$. The possible influence of these transformations on the seismic slip mode, its dynamics, and the mechanical instability causes in the fault are discussed.

Key words: slickensides, gouge, feldspar hydrolysis, seismic slip, mechanical instability.

\section{Введение}

Вопросы влияния процессов структурно-текстурных и минерально-вещественных преобразований горных пород в условиях локализованных деформаций на механические и реологические свойства геоматерала приобретают особую важность при оценке условий подготовки и механизмов реализации сейсмических подвижек в земной коре. Эти оценки включают множество взаимосвязанных и взаимозависимых аспектов, характеризующих динамику подвижки, условия зарождения и проявления механической неустойчивости в зоне разлома, факторы и механизмы ослабления и упрочнения разломного материала в ходе смещения, параметры состояния среды, способствующие или препятствующие этому, а также оценки глубинности очаговых зон и особенностей проявления процессов на разных уровнях коры [Морозов и др., 2016; 2018 a; 2018 б]. В рамках перечисленных аспектов исследований предметом изучения являются разнообразные продукты преобразований породного вещества (сейсмиты), происходящих при сейсмических (1-5 м/сек), или близких к 
ним, скоростях смещений в зонах разломов. Эти продукты, весьма разнообразные по своему составу, сложению и морфологическому выражению, в зависимости от глубины, условий и механизмов формирования, включают глинки трения, пленки зеркал скольжения, брекчии, катаклазиты, милониты, псевдотахилиты и другие типы сейсмитов. Их целенаправленное изучение, как наиболее достоверных указателей на сейсмический характер подвижки в зонах палеоземлетрясений, позволяет достаточно подробно охарактеризовать те процессы, что ослабляют поверхность сместителя и укоряют движение, или, наоборот, приводят к упрочнению разломной матрицы и соответствующему замедлению или к приостановке сдвига, т. е. по сути дела, дать оценки динамики подвижки и факторов, оказывающих на это влияние.

В развитие ранее проведенных исследований по особенностям преобразований пород терригенной природы в зоне верхнего перехода от асейсмического к сейсмическому режиму разрывообразования в земной коре, в ходе которых нами были изучены зеркала скольжения и глинки трения по глинам и суглинкам, аркозовым песчаникам и метапесчаникам, а также шунгитам [Морозов и др., 2016; 2018 а; 2018 б], этот ряд был дополнен зеркалом скольжения в красноцветном неизмененном песчанике. Значительное обогащение его субстрата окислами железа давало возможность оценить их роль и влияние на характер и направленность минеральных превращений на фоне деформаций, а также на механические свойства разломной матрицы.

\section{Результаты аналитических работ}

Зеркала скольжения в красноцветных песчаниках (рис. 1) девонской формации Old Red Sandstones [Dineley, 1992; Hillier et al., 2006] были найдены и апробированы нами на о. Бьют (Шотландия), как пример сейсмогенных преобразований полимиктовых осадочных пород приповерхностного залегания и высокой степени консолидации (литификации), в тоже время еще не затронутых метаморфизмом. По своему происхождению это типичные образования моллассоидного типа, формирование которых происходило на окраине Шотландского нагорья во время так называемой грампианской орогении порядка 470 млн. лет назад. Состав этих пород пестрый, полимиктовый и определяется присутствием приблизительно в равных пропорциях обломков кварца (моно- и поликристаллических модификаций), натрового и калиевого полевых шпатов, рудных фаз в незначительном по объему (10-20 \%) глинистом цементе состава иллит-смектит, пропитанном окислами железа (рис. 2).

Поверхности зеркал скольжения с хорошо проявленными бороздами скольжения и штриховкой, как правило, содержат примазки гематита и пленки тонко-листоватого материала, обогащенного слюдистыми чешуйками (см. рис. 1). Аналитическое сравнительное изучение составов исходного песчаника и пленки зеркала скольжения проводилось с помощью рентгено-дифракционного анализа порошковых препаратов на дифрактометре STOE в геометрии «на просвет». Рабочий режим - 40 кB-30 mA, кобальтовое излучение, детектор - linear PSD, монохроматор-Ge, тип съёмки:
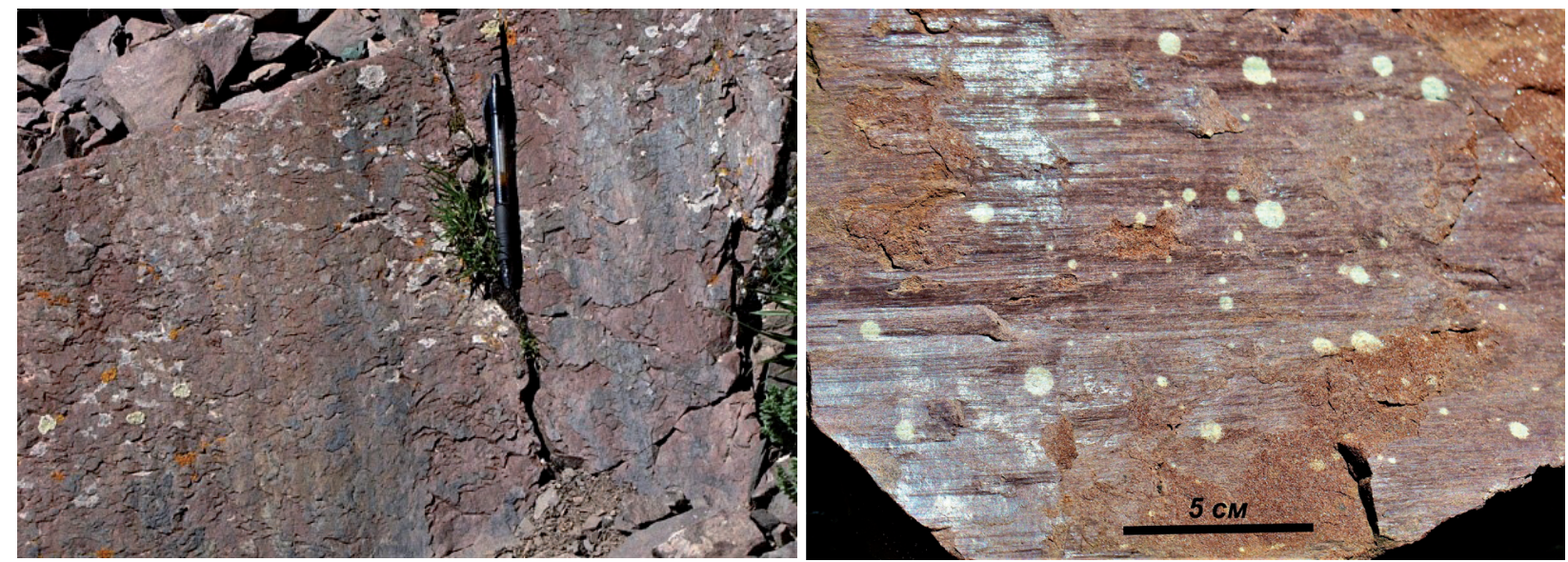

Рис. 1. Зеркала скольжения в красноцветных песчаниках о-ва Бьют (Шотландия).

Fig. 1. Slickensides in the Old Red Sandstones of the Isle of Bute (Scotland). 

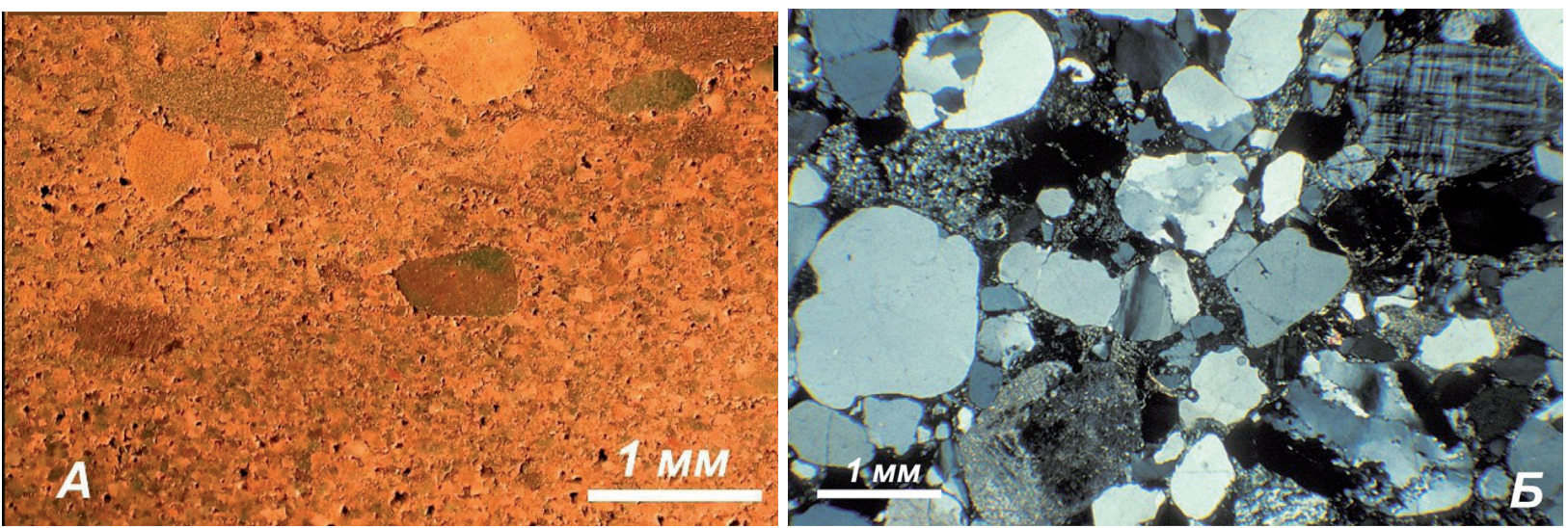

Рис. 2. Псаммитовая структура красноцветных песчаников в образце (а) и в шлифе (б).

Fig. 2. Psammitic structure of the Old Red Sandstones in a specimen (a) and in a thin section (b).

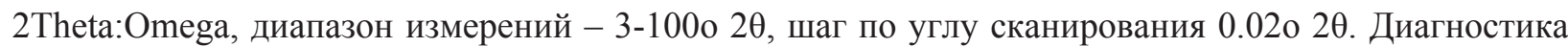
минерального состава проводилась методом сопоставления экспериментального и эталонных спектров из базы данных PDF-2 в программных пакетах WinXPow и Crystal Impact Match и базы данных COD в программном пакете QualX. Параллельно был проведен анализ исходной породы и зеркала скольжения в недробленных образцах. Сравнительные результаты этих двух способов аналитики приведены в таблице 1.

Таблица 1. Результаты минерально-фазового анализа песчаника о. Бьют и зеркала скольжения (3С) в нем.

Table 1. Results of mineral-phase analysis of sandstone and slickenside from the Isle of Bute.

\begin{tabular}{|c|c|c|c|}
\hline Метод & Название минерала & Песчаник & $3 \mathrm{C}$ \\
\hline \multirow{5}{*}{$\begin{array}{c}\text { XRD в } \\
\text { недробленом } \\
\text { образце }\end{array}$} & Кварц (Q) & $78.6 \%$ & $82.1 \%$ \\
\hline & Альбит (Alb) & $13.5 \%$ & $5.7 \%$ \\
\hline & Микроклин (Мic) & $7.9 \%$ & - \\
\hline & Мусковит (гидрослюда) & $0,00 \%$ & $9.2 \%$ \\
\hline & Гематит & - & $3.1 \%$ \\
\hline \multirow{5}{*}{$\begin{array}{c}\text { XRD в } \\
\text { глинистой } \\
\text { фракции } \\
<0.001 \text { мм }\end{array}$} & Кварц & $76.64 \%$ & $82.07 \%$ \\
\hline & Альбит & $13.2 \%$ & $5.68 \%$ \\
\hline & Микроклин & $7.67 \%$ & - \\
\hline & Гематит & - & $3.05 \%$ \\
\hline & Мусковит & $2.48 \%$ & $9.20 \%$ \\
\hline
\end{tabular}

Исходя из полученных данных можно заключить, что при деформации в зоне подвижки произошло существенное изменение минерально-фазового и химического состава в сравнении с исходным песчаным матриксом. В два с лишним раза сократилось содержание альбита и полностью исчез микроклин, но при этом в значительном количестве появился мусковит (или гидрослюды) и сформировалась пленка чисто гематитового состава. Совершенно очевидно, что здесь произошли процессы гидролиза полевых шпатов, которые в природе имеют самое широкое распространение при выветривании пород, а также при формировании глинок трения в разломах. При наличии в системе окислов железа и рудых минералов можно рассмотреть два варианта протекания реакции гидролиза полевых шпатов, которые сопровождаются формированием гематита и приращением доли $\mathrm{SiO}_{2}$ :

1) Реакция с привлечением из раствора $\mathrm{Fe}^{2+}{ }_{\text {aq }}$ Она требует кислорода для окисления железа и является окислительной. Кроме того, обычно при гидролизе полевых шпатов образуется много диоксида кремния, однако в нашем примере зафиксирован не очень большой его прирост - порядка $5 \%$. С учетом известных эмпирических и экспериментальных данных о том, что значительная его часть, как правило, выносится из зоны сейсмогенной подвижки в виде растворимого силикагеля - 
ортокремниевой кислоты $\mathrm{H}_{4} \mathrm{SiO}_{4}$ [Herrington, 1993; Di Toro, 2011; Kirkpatrick, 2013] реакцию гидролиза можно записать в следующем виде:

$$
\begin{aligned}
& 2 \mathrm{NaAlSi}_{3} \mathrm{O}_{8}+\mathrm{KAlSi}_{3} \mathrm{O}_{8}+11 \mathrm{H}_{2} \mathrm{O}+\mathrm{O}_{2}+2 \mathrm{Fe}^{2+}{ }_{\text {aq }}=\mathrm{KAl}_{3} \mathrm{Si}_{3} \mathrm{O}_{10}(\mathrm{OH})_{2}+\mathrm{SiO}_{2}+5 \mathrm{H}_{4} \mathrm{SiO}_{4 \text { aq }}+\mathrm{Fe}_{2} \mathrm{O}_{3}+2 \mathrm{Na}^{+}{ }_{\text {aq }} \\
& \text { Альбит Микроклин Мусковит Кварц Ортокремн Гематит }
\end{aligned}
$$

При этом, расчет объемного эффекта реакции свидетельствует об уплотнении материала зоны подвижки $-\Delta \mathbf{V}=-\mathbf{1 3 5} \mathbf{c m}^{3}$ (табл. 2).

Таблица 2. Объемный эффект реакции гидролиза полевых шпатов песчаника с участием оксида железа.

\begin{tabular}{|c|c|c|c|c|c|c|c|c|}
\hline & $\mathrm{n}$ & $\mathrm{Vcm}^{3} /$ моль & Vреаг.см ${ }^{3}$ & & $\mathrm{n}$ & $\mathrm{Vcm}^{3} /$ моль & Vпрод.см ${ }^{3}$ & $\Delta \mathrm{V}=\left(\right.$ Упрод-реаг), $\mathrm{cm}^{3}$ \\
\hline Alb & 2 & 100 & 200 & Mus & 1 & 141 & 141 & \multirow{4}{*}{-115} \\
\hline Mic & 1 & 109 & 109 & Q & 1 & 23 & 23 & \\
\hline & & & & Hem & 1 & 30 & 30 & \\
\hline$\sum$ & & & 309 & $\sum$ & & & 194 & \\
\hline
\end{tabular}

Table 2. The volume effect of the feldspar's hydrolysis reaction with iron oxide.

2) Если предположить в исходном песчанике присутствие гидроокислов окисного железа в виде твердых минералов гетита или лепидокрокита, то они обычно сопровождаются растворимыми комплексами железа. В этом случае полевые шпаты подвергаются гидратации, а гидроокислы железа - дегидратации:

$2 \mathrm{NaAlSi}_{3} \mathrm{O}_{8}+\mathrm{KAlSi}_{3} \mathrm{O}_{8}+\mathrm{FeO}(\mathrm{OH})+10 \mathrm{H}_{2} \mathrm{O}+\mathrm{Fe}(\mathrm{OH})_{2}^{+}=\mathrm{KAl}_{3} \mathrm{Si}_{3} \mathrm{O}_{10}(\mathrm{OH})_{2}+\mathrm{SiO}_{2}+5 \mathrm{H}_{4} \mathrm{SiO}_{4 a q}+\mathrm{Fe}_{2} \mathrm{O}_{3}+2 \mathrm{Na}_{\text {aq }}^{+}$ Альбит Микроклин Гетит Мусковит Кварц Ортокремн Гематит

Объемный эффект реакции в этом случае получается еще значительней - происходит большее уплотнение материала в зоне подвижки по сравнению с исходным песчаником $-\boldsymbol{\Delta V}=\mathbf{- 1 3 5 \mathbf { c m } ^ { 3 }}$ (табл. 3).

Таблица 3. Объемный эффект реакции гидролиза полевых шпатов песчаника с участием гидроокислов окисного железа.

\begin{tabular}{|c|c|c|c|c|c|c|c|c|}
\hline & $\mathrm{n}$ & $\mathrm{V} \mathrm{cm}^{3} /$ моль & Vреаг.см ${ }^{3}$ & & $\mathrm{n}$ & 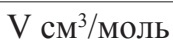 & Vпрод.см ${ }^{3}$ & $\Delta \mathrm{V}=(\mathrm{V} п р о д-\mathrm{V}$ еаг $), \mathrm{cm}^{3}$ \\
\hline Alb & 2 & 100 & 200 & Mus & 1 & 141 & 141 & \multirow{4}{*}{-135} \\
\hline Mic & 1 & 109 & 109 & Q & 1 & 23 & 23 & \\
\hline Гет & 1 & 20 & 20 & Hem & 1 & 30 & 30 & \\
\hline$\sum$ & & & 329 & $\sum$ & & & 194 & \\
\hline
\end{tabular}

Table 3. The volume effect of the feldspar's hydrolysis reaction with the participation of iron hydroxides.

\section{Механические следствия структурно-вещественных преобразований в зоне подвижки}

На основе полученных результатов, мы можем констатировать, что разрывная подвижка стимулировала и локализовала в зоне разлома реакции разложения полевых шпатов и формирование гидрослюд в сочетании с гематитом. Если допустить, что все это происходило во время сейсмического цикла, то такие преобразования должны были неизбежно влиять на динамику смещения и возникновение механической неустойчивости в разломе. Прежде всего, это касается объемных эффектов реакции гидролиза полевых шпатов. Так как их процентное содержание в породе варьирует от места к месту, то следует ожидать и разницу в степени уплотнения матрикса, что должно повлиять на неустойчивость процесса подвижки в теле разлома. Точно также, если доля формирующихся гидрослюд или мусковита в разломной матрице, обладающих пониженными значениями модуля сдвига, изменчива в плоскости сместителя, то это усилит неустойчивость подвижки. Существенную роль в ослаблении разлома и в облегчении смещения по нему должно сыграть выделение в ходе преобразований песчаника пленок силикагеля, чье присутствие установлено во многих активных сейсмогенных разломах [Goldsby, Tullis. 2002; Kirkpatrick et al., 2013; Faber et al., 2014], и 
который, как показывают эксперименты [Di Toro et al., 2004], снижает трение при смещении практически до нуля.

Работа выполнена в рамках проекта Программы фундаментальных научных исследований № 8 Президиума РАН.

\section{Литература}

1. Морозов Ю.А., Букалов С.С., Лейтес Л.А. Механохимические преобразования шунгита в зоне динамической подвижки // Геофизические исследования. 2016. Т. 17. № 2. С. 5-18.

2. Морозов Ю.А., Смульская А.И., Кулаковский А.Л., Матвеев М.А. Структурно-вещественные записи палеоземлетрясений в терригенных породах: анализ и интерпретация // Физика Земли. 2018 а. № 1. С. 3-25.

3. Морозов. Ю.А., Матвеев М.А., Смульская А.И., Кулаковский А.Л. К вопросу о генезисе псевдотахилитов // Труды Ферсмановской научной сессии ГИ КНЦ РАН. 2018 б. № 15. С. 255-258. doi: 10.31241/ FNS.2018.15.063.

4. Dineley D.L. Devonian / Geology of England and Wales. (P. McL. D. Duff and A.J. Smith, editors). The Geological Society, London, Bath.1992. P. 179-205.

5. Di Toro, G., Goldsby D. L., Tullis T. E. Friction falls towards zero in quartz rock as slip velocity approaches seismic rates // Nature. 2004. 427 (6973). P. 436-439.

6. Di Toro, G., R. Han, T. Hirose, et. al. Fault lubrication during earthquakes // Nature. 2011.471 (7339). P. 494-498.

7. Faber C., Rowe C., Miller J. et al. Silica gel in a fault slip surface: Field evidence for palaeo-earthquakes? // Journal of Structural Geology. 2014. V. 69. P. 108-121.

8. Goldsby D.L., Tullis T.E. Low frictional strength of quartz rocks at subseismic slip rates // Geophysical Research Letters. 2002. V. 29 (17). P. 1844.

9. Herrington, R. J., Wilkinson J. J. Colloidal gold and silica in mesothermal vein systems // Geology. 1993. V. 21 (6). P. 539-542.

10. Hillier S., Wilson M.J., Merriman R. J. Clay mineralogy of the Old Red Sandstone and Devonian sedimentary rocks of Wales, Scotland and England // Clay Minerals. 2006. V. 41 (1). P. 433-471.

11. Kirkpatrick J.D., Rowe C.D., White J.C., Brodsky E.E. Silica gel formation during fault slip: Evidence from the rock record // Geology. 2013. V. 41 (9). P. 1015-1018. 